\title{
Relato de experiência: avaliação psicológica de uma criança vítima de abuso sexual fundamentada no psicodrama
}

\author{
Experience report: psychological evaluation of a child victim of sexual abuse \\ through the use of psychodrama
}

\section{Estudio de caso: evaluación psiquiátrica de la niña víctima de abuso sexual basada en el psicodrama}

\author{
Letícia Nagel Bérgamo \\ Universidade Federal do Paraná (UFPR)-e-mail: psi.leticianb@gmail.com
}

\author{
Márcia Pereira Bernardes \\ Locus Psicodrama - e-mail: marcia@locuspsicodrama.com.br
}

\section{Resumo}

Trata-se do processo de avaliação psicológica realizado com uma criança de cinco anos e sua família em uma instituição de atendimento, diante da denúncia de abuso sexual que envolveu a criança e o padrasto. Foram realizadas oito sessões de avaliação, fundamentadas no Psicodrama, nas quais foram identificados o abuso, suas consequências e o papel dos membros do grupo familiar nesse processo. O objetivo foi compreender a dinâmica abusiva, verificando fatores de risco e proteção no contexto familiar.

Palavras-chave: Avaliação psicológica. Psicodrama. Criança. Abuso sexual.

\section{Abstract}

This article presents the process of a psychological evaluation with a child of five years and her family, in a care institution before a complaint of sexual abuse involving the child and the stepfather. The goal was to understand the abusive dynamics checking risk and protective factors in the family context. Eight evaluation sessions were accomplished using psychodrama, which revealed the abuse, its consequences and the roles of the family members in this process.

Keywords: Psychological evaluation. Psychodrama. Child. Family. Sexual abuse.

\section{Resumen}

Este artículo presenta el proceso de evaluación psicológica que se lleva a cabo con una niña 
de cinco años y su familia, en una institución, sobre la denuncia de abuso sexual con la niña y su padrastro. Se realizaron ocho sesiones de evaluación, basada en el psicodrama. Se identificó el abuso, sus consecuencias y el papel de los miembros de la familia en el proceso. El objetivo fue conocer la dinámica del abuso, los factores de riesgo y la protección en el contexto de la familia.

Palabras-clave: Evaluación psicológica. Psicodrama. Niña. Familia. Abuso sexual.

\section{INTRODUÇÃO}

O abuso sexual contra crianças e adolescentes tem sido considerado um problema de saúde pública, apresentando alta incidência na população, o que pode repercutir em prejuízos para o desenvolvimento psicológico e social das vítimas e de seus familiares (HABIGZANG e CAMINHA, 2004; HABIGZANG et al., 2006). Caracteriza-se como todo ato ou jogo sexual, no qual aquele que agride apresenta desenvolvimento psicossexual mais adiantado que a vítima e tem por finalidade estimular sexualmente a criança/adolescente ou obter prazer sexual. A forma pode variar de atos em que não existam contato físico, mas envolvem o corpo (assédio e exibicionismo), aos diferentes tipos de contato físico com ou sem penetração (AZEVEDO e GUERRA, 1989; HABIGZANG et al., 2006). Pode ocorrer de modo intrafamiliar ou extrafamiliar, dependendo se o autor da agressão faz parte ou não do convívio familiar. Trata-se de um fenômeno complexo, que abrange aspectos legais, socioculturais e de saúde; por isso é indicada a intervenção de diversas áreas e instituições de forma articulada (FURNISS, 2002; SANDERSON, 2004).

O abuso sexual pode configurar-se como um fator de risco para o desenvolvimento de crianças/adolescentes. $\mathrm{O}$ risco " [...] está associado às características ou aos eventos que podem levar a resultados ineficazes, enfraquecendo a pessoa diante da situação de estresse. Em contrapartida, fatores de proteção inibem a intensidade desse risco [...]" (HABIGZANG et al., 2006, p. 380), possibilitando e facilitando o curso de desenvolvimento da criança/adolescente. Nesse contexto, cabe ao profissional da psicologia avaliar a dinâmica relacional e identificar fatores de risco e proteção ao desenvolvimento. $\mathrm{O}$ psicodrama apresenta fundamentos teóricos e metodológicos que possibilitam essa avaliação.

O presente artigo tem como objetivo apresentar a experiência da autora na condução de uma avaliação psicológica realizada com uma criança de cinco anos, vítima de abuso sexual, e sua família, utilizando o psicodrama como fundamento teórico e metodológico.

\section{MÉTODO}

A avaliação psicológica sustentada na teoria psicodramática foi realizada em uma instituição que presta atendimento a famílias e indivíduos com direitos violados. Os participantes da avaliação foram a criança e sua família: Carolina, cinco anos, é fillha de Maria e Daniel ${ }^{2}$, separados há três anos e meio. Há três anos a mãe constituiu novo relacionamento com Pedro, acusado de praticar abusos sexuais contra Carolina.

\section{PROCEDIMENTOS DA AVALIAÇÃO PSICOLÓGICA}

2 Todos os nomes apresentados são fictícios. 
Inicialmente, foram coletadas informações na instituição onde foi feita a denúncia do abuso sexual. Foram realizadas oito sessões de atendimento que contemplaram: duas entrevistas com a mãe, quatro sessões com a criança, uma sessão conjunta da criança com a mãe, uma sessão com a mãe e a criança após audiência e uma sessão para devolutiva da avaliação, além da articulação com a rede de atendimento (escola e posto de saúde). O padrasto e o pai foram chamados, mas não compareceram.

As sessões de atendimento foram desenvolvidas utilizando o referencial psicodramático. A estrutura das sessões apoiou-se no tripé: contextos (social e dramático), instrumentos (cenário, protagonista e egos-auxiliares) e etapas (aquecimento, dramatização e comentários). De acordo com Petrilli (2002), é necessário que a intervenção com crianças menores de dez anos ocorra em um contexto dramático. Quanto aos instrumentos, o cenário geralmente é lúdico, a protagonista é a própria criança e o ego-auxiliar, o terapeuta. Também são respeitadas as diferenças quanto às etapas da sessão, pois com crianças a fase de aquecimento quase não se destaca. Conforme recomenda Petrilli (2002), os terapeutas devem atuar dentro dos papéis que lhes são atribuídos pelas crianças, fazendo intervenções que julgarem necessárias, e os comentários devem ser feitos durante as dramatizações (GONÇALVES, 1988). As técnicas utilizadas basearam-se nas fases de desenvolvimento infantil propostas por Moreno (2003): duplo, espelho e inversão de papéis, além de jogos, histórias e brincadeiras criadas espontaneamente (GONÇALVES, 1988). A análise dos dados foi realizada por meio da psicodinâmica dos papéis, tecendo também considerações sobre o desenvolvimento do EU em um processo inter-relacional.

\section{DESCRIÇÃO DA INTERVENÇÃO E DOS DADOS COLETADOS}

\section{a) Fragmentos das entrevistas com a mãe ( $1^{\mathrm{a}}$ e $2^{\mathrm{a}}$ sessões $)$}

Da denúncia: Maria foi chamada na escola porque Carolina estava apresentando comportamentos inadequados (falta de limite, comportamento sexualizado). A mãe foi orientada a conversar com a filha para verificar se estava sofrendo abuso sexual. Carolina contou para a mãe que o padrasto a colocava para dormir com ele quando ela saía para trabalhar. Ele mexia em seu corpo com a mão e com o órgão genital. A mãe duvidou do que a filha lhe contara, teve, então, uma conversa com Pedro, que confirmou o exposto. Como Pedro tinha pedido perdão, Maria achou que isso não voltaria a acontecer; desse modo, manteve o relacionamento conjugal. Em reunião na escola, Maria relatou que a filha confirmara que havia sido vítima de abuso sexual, e a denúncia foi encaminhada ao Conselho Tutelar e posteriormente ao Serviço de Atendimento e ao Ministério Público. Pedro foi afastado do lar por mandado judicial. O casal mantinha contato por telefone e ainda se consideravam casados. A mãe não contou sobre a situação para a família paterna da criança, pois temia perder a guarda da filha.

Do histórico: Maria era vítima de violência física e psicológica perpetrada pelo pai. Iniciou o relacionamento com Daniel na época de sua adolescência e passou a viver em união estável com ele, visando se proteger do comportamento agressivo de seu pai. Logo, o casal teve a filha Carolina. Sobre ser mãe, Maria afirma: "Até hoje acho que sou mais uma amiga ou irmã do que uma mãe" (sic). Na separação, ficou acordado que a criança passaria quinzenalmente os finais de semana com o pai. No entanto, quando visitava o pai, Carolina permanecia mais tempo sob os cuidados dos avós paternos. Maria iniciou o relacionamento com Pedro e relatou que ele: "era como um pai pra mim, o pai que eu sempre quis ter e não tive" (sic). Afirmou que Pedro a auxiliou muito profissional e financeiramente, bem como nos 
cuidados com Carolina, que até o chamava de pai.

b) Sessões de atendimento com a criança

Fragmentos da terceira sessão: Carolina entra na sala de atendimento com facilidade, apresento o local e logo ela diz que quer brincar. Ao ser abordada sobre o motivo de estar frequentando o Serviço, novamente ela diz que quer brincar. Monta o cenário: uma casa com uma cozinha e um quarto com duas camas. No processo de escolha dos personagens, a protagonista pega vários bonecos, coloca-os na boca, aproxima um boneco do outro esfregando o corpo, entre bonecos adultos e entre adultos e crianças. Dá-se a primeira cena mediante atos. Carolina prossegue no processo de escolha dos personagens e escolhe cinco bonecos: pai, mãe, filha e mais dois adultos que não nomeia. Ela coloca esses bonecos no cenário: o pai, a mãe e a filha estão no quarto e dois adultos na cozinha. Desenvolve-se a segunda cena: o dia está amanhecendo, os personagens estão dormindo. A mãe acorda e vai para a cozinha, e a criança passa a dormir com o pai. Novamente a cena se desenvolve mediante atos. Essa sessão corrobora com Petrilli (2002) ao afirmar que no Psicodrama com crianças a dramatização é constante durante o tempo da sessão.

Fragmentos da quarta sessão: a criança monta o cenário: uma casa com quarto, cozinha e sala. Ao tomar contato com os bonecos, desenvolve uma cena que envolve atos sexuais entre os bonecos. A intervenção da terapeuta ocorre fazendo assinalamentos sobre o corpo dos bonecos, e a criança demonstrou curiosidade em relação aos órgãos genitais. Brincamos de esconder os órgãos genitais e adivinhar qual era o boneco menino e qual era a menina. Posteriormente, Carolina apresenta-se de forma relaxada e encena um ato sexual, praticando-o com um boneco adulto que afirmou ser o pai (padrasto).

Fragmentos da quinta sessão: a criança faz o desenho da família e apresentando certa resistência desenha ela e a mãe. Posteriormente, inicia um desenho livre e seu relato é o seguinte:

$\mathrm{C}^{3}$ - Uma bela menina tava cheirando uma flor, era uma princesa, ela não tinha casa, tava morando na rua [...]. Um dia ela foi dormir e apareceu um lobisomem e no outro dia veio o monstro, e ela se assustou por causa do monstro [...]. A princesa tava doída, porque o monstro tinha machucado ela.

$\mathrm{T}^{4}-$ Precisamos cuidar da princesa...

C - Acho que sim... ela tá fraquinha... vou pegar a princesa! (Escolhe um fantoche para representá-la.)

$\mathrm{T}$ - (Pego o fantoche da fada.) Olá, princesa! Sou a fada!

$\mathrm{C}$ - Oi, fada, onde você mora?

$\mathrm{T}$ - No mundo encantado, eu vim de lá pra ficar com você o tempo que precisar...

$\mathrm{C}-\mathrm{O}$ lobo mau tá vindo! (Pega o fantoche do lobo.)

T - Olha... eu trouxe do mundo encantado esse saco de pedrinhas mágicas. Essa é a pedra da coragem, é a pedra que os guerreiros usam e as princesas também, quando acham que estão em perigo e precisam afastar os monstros ou os lobos do seu reino. Pedra do mundo encantado, encha de coragem o coração dessa princesa, para que ela tenha força pra enfrentar o lobo!

C - (Lobo): Vim te pegar. (Carolina no papel de lobo começa a agredir a princesa.) (Carolina no papel de princesa): Não vai, não, eu sou forte!

3 C: Refere-se à criança.

4 T: Refere-se à terapeuta. 
T - (Fada): Isso mesmo! Saia daqui, lobo mau!

(A princesa e o lobo brigam e o lobo morde a princesa.)

$\mathrm{T}$ - (Fada): Lobo! Para de incomodar a princesa!

$\mathrm{C}$ - (Princesa): Sai daqui, lobo mau, volte pra floresta... mágicos!

T - (Fada): Varinha de condão do mundo encantado, dê à princesa superpoderes

(A princesa empurrou o lobo para longe.)

$\mathrm{C}$ - (Princesa): Pronto! Voltou pra floresta!

$\mathrm{T}-$ (Fada): Ótimo! Como você está, princesa?

$\mathrm{C}-$ (Princesa): Melhor.

O desenho funcionou como aquecimento, desencadeando a história e a dramatização, apresentando conteúdo da relação agressor-vítima.

c) Sessão conjunta com a mãe e a criança

Nessa sessão, foi proposta uma atividade dirigida: colagem de figuras, representando a si mesma e a outra. O objetivo foi verificar e estimular a percepção de cada uma sobre si mesma e a outra: reconhecimento do $\mathrm{Eu}$ e do $\mathrm{Tu}$ e indicadores do fator tele.

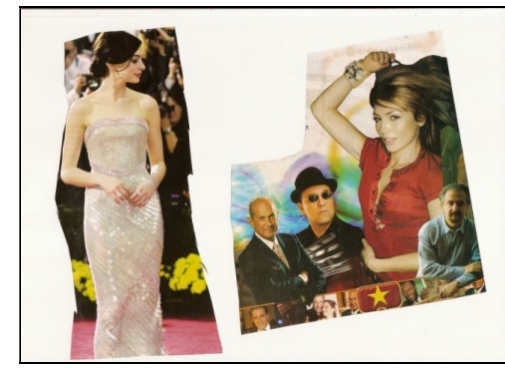

Figura 1 - Colagem da criança Da esquerda para direita: representação da mãe e da criança, respectivamente

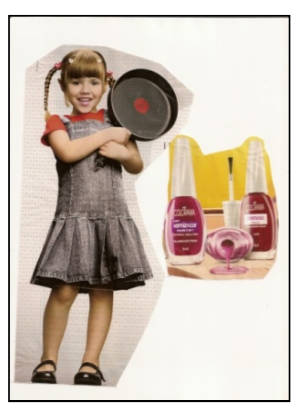

Figura 2 - Colagem da mãe Da esquerda para direita: representação da criança e da mãe, respectivamente

A criança representou ela mesma como uma mulher adulta, sensual, rodeada de homens, e a mãe ao lado observando. A mãe, para representar a si mesma, escolheu um esmalte derrubado.

d) Sessão após audiência judicial

Na mesma data em que se desenvolveu a sétima sessão, ocorreu uma audiência para tratar da responsabilização do padrasto. Maria esperava que ele comparecesse em juízo e confessasse o abuso sexual. No entanto, Pedro fugiu e Maria optou pela separação conjugal. Carolina sentiu-se autorizada a falar sobre a vivência do abuso sexual, que ocorreu por meio da técnica do solilóquio. Carolina apresentou angústia relacionada à responsabilização do padrasto e sentiu-se culpada por deixar a mãe triste por causa da separação. Embora tenha utilizado materiais lúdicos, trabalhou-se no contexto social, explicando as regras de convivência e a responsabilidade do adulto no abuso sexual.

e) Entrevista devolutiva 
Começou-se a preparação da criança para o início da psicoterapia em grupo. Foi recomendada à mãe psicoterapia para ela e para a filha. Esta indicação baseou-se na identificação de fatores de risco (dinâmica relacional do casal baseada na necessidade de satisfação individual; ausência de hierarquia intergeracional; vínculo transferencial na relação mãe-filha; entraves no desempenho do papel de mãe, abuso sexual da criança) e no impacto decorrente do abuso sexual (atuação da criança basicamente no papel sexual e adulto).

\section{DISCUSSÃO E ANÁLISE}

Para compreender a vitimização em uma família, deve-se "observar o fenômeno do ponto de vista dos pais" (FERRARI e VECINA, 2002, p. 43). No caso em estudo, o contexto formado pela mãe e pelo padrasto refere-se a um grupo familiar "caracterizado pelas metas de satisfação egocêntricas das necessidades individuais de cada um" (FERRARI e VECINA, 2002, p. 92). Dessa forma, existe uma exclusão das necessidades da criança. Exemplo disso pode ser observado por meio das falas trazidas pela mãe no momento da entrevista, quando se refere à filha: "acho que sou mais uma amiga ou uma irmã, do que uma mãe" (sic) e quando se refere ao companheiro: "era como um pai pra mim, o pai que eu queria ter e não tive" (sic). Maria interagia com o marido, delegando a ele a função psicológica do cuidado. Segundo Bustos (1990), os papéis experimentados pelo sujeito (atuados e não atuados no presente) interagem e se agrupam basicamente de acordo com as experiências de receber (clúster um), dar (clúster dois) e compartilhar (clúster três), formando as bases para o movimento da atuação dos papéis. A dinâmica de desempenho dos papéis atuados pela mãe apresentou sua localização no clúster um, que denota dependência e necessidade de receber (afeto, atenção, direção etc.). Isso interferiu no enfraquecimento do desempenho do papel de mãe, pois, ao desempenhá-lo, Maria necessitou oferecer cuidado, proteção e assumir responsabilidades perante o outro. Maria não reconheceu as necessidades da filha e colocouse em uma posição de igual para igual com Carolina, aparecendo a ausência da hierarquia intergeracional no vínculo mãe-filha. Coube ao padrasto o poder de direção dos vínculos. Ele desempenhou a função de cuidador de Maria, complementando o jogo de papéis, e convocou a criança a interagir na relação, desempenhando o contrapapel de mulher, visto que desempenhava com ela o papel de homem. A mãe e o padrasto viveram uma vinculação subjetiva transferencial com a filha; dessa forma, não houve o respeito pela condição da criança, que foi submetida à trama familiar da vitimização.

Carolina encontrava-se imersa em relações transferenciais estabelecidas pelos responsáveis e foi considerada adulta. A criança apresentou-se sem direção, sem os limites necessários que favorecem a adequada percepção de si e do outro, mostrou-se agitada, confusa, erotizada, demonstrou medo e desproteção. A criança encontrou-se na fase de desenvolvimento emocional relacionada ao Reconhecimento do Eu. Nessa fase, há integração no psiquismo dos três conjuntos de papéis: psicossomáticos, psicodramáticos e sociais, havendo a estruturação do EU. Os três conjuntos de papéis vão compor os aspectos biopsicossociais de um mesmo papel. Durante o processo de avaliação, pôde-se observar que a criança inicialmente desenvolveu dramatizações mediante atos, depois por meio de recursos de faz de conta e ao final utilizou a linguagem verbal para expressar o que acontecia. Assim, sua atuação demonstrou gradativamente as três unidades constituintes do papel: corpo (psicossomático), fantasia (psicodramático) e realidade social (social), apresentando o EU de forma integrada, porém se reconhecendo basicamente mediante atuação no papel sexual e adulto. Carolina desenvolveu percepções distorcidas em relação a si mesma.

A mãe se deu conta de que a filha estava se percebendo como adulta por meio da técnica da colagem de gravuras realizada na sessão conjunta e do processamento dessa sessão. 
Percebeu também que ela estava agindo com a criança como amiga ou irmã, dado coletado na entrevista que foi retomado posteriormente. Admitiu que estava se sentindo "atropelada" em seus desejos (técnica da colagem de gravura - esmalte derrubado) e necessitava de um espaço para se desenvolver e se fortalecer. A ressignificação da vitimização, o resgate de relações télicas, o desenvolvimento de papéis pouco desenvolvidos (mãe, filha etc.) e a introjeção de novos modelos relacionais foram aspectos apontados para serem trabalhados em futuros processos psicoterapêuticos tanto para a criança, como para a mãe.

\section{CONSIDERAÇÕES FINAIS}

A avaliação psicológica utilizou recursos metodológicos do Psicodrama: as sessões se estruturam no tripé contextos, instrumentos e etapas; as etapas das sessões foram identificadas; atuou-se com a criança principalmente no contexto dramático e com a mãe, no contexto social. As técnicas utilizadas favoreceram o acesso a conteúdos que forneceram dados para uma análise da criança e das relações familiares. A dinâmica relacional desenvolvida pelos responsáveis, que compensavam suas necessidades individuais por meio dos vínculos transferenciais estabelecidos, não oferecendo um olhar de cuidado e proteção à criança, a qual foi submetida a trama da vitimização. A violência gerou impactos no desenvolvimento emocional da criança, que se reconheceu no papel sexual adulto, apresentando comportamentos inadequados à fase infantil. Dessa maneira, o contexto familiar oferecia riscos ao seu desenvolvimento. Foi necessária a intervenção do estado para romper com as formas relacionais estabelecidas e a psicoterapia foi apontada como um dos caminhos possíveis para a construção e o desenvolvimento de novos modelos de interação, capazes de garantir à criança a proteção necessária.

\section{REFERÊNCIAS}

AZEVEDO, M. A.; GUERRA, V. N. A. Crianças vitimizadas: A síndrome do pequeno poder. São Paulo: IGLU, 1989.

BUSTOS, D. M. Perigo amor à vista! Drama e psicodrama de casais. São Paulo: Aleph, 1990.

FERRARI, D. C. A.; VECINA, T. C. C. O fim do silêncio na violência intrafamiliar: teoria e prática. São Paulo: Ágora, 2002.

FURNISS, T. Abuso sexual da criança: Uma abordagem multidisciplinar. Porto Alegre: Artes Médicas, 2002.

GONÇALVES, C. S. Psicodrama com crianças: uma psicoterapia possível. São Paulo: Ágora, 1988.

HABIGZANG, L. F.; CAMINHA, R. M. Abuso sexual contra crianças e adolescentes: conceituação e intervenção clínica. São Paulo: Casa do Psicólogo, 2004.

HABIGZANG, L. F. et al. Fatores de risco e de proteção na rede de atendimento a crianças e adolescentes vítimas de violência sexual. Psicologia: Reflexão e Crítica, Porto Alegre, v. 19, n. 3, 2006, p. 379-386.

MORENO, J. L. Psicodrama. São Paulo: Cultrix, 2003.

SANDERSON, C. Abuso sexual em crianças: fortalecendo pais e professores na proteção a 
crianças contra abusos sexuais e pedofilia. São Paulo: M Books, 2004.

PETRILLI, S. R. A. Psicodrama com crianças: raízes, transformações e perspectivas. 2002. Disponível em:

$<$ www.febrap.org.br/pdf/Psic Etica riancas raizes transformaces.pdf $>$. Acesso em: fev. 2012.

Nota: Trabalho apresentado à Locus Psicodrama em forma de monografia, no curso de Especialização em Psicodrama - Foco Psicoterápico. Agradeço à Locus pela oportunidade de vivenciar e aprender o psicodrama, à Márcia Pereira Bernardes e à Mariângela Vendruscolo Currlin pelo incentivo e pela orientação.

Recebido: 30/03/2014

Aceito: 04/03/2016

Letícia Nagel Bérgamo. Psicóloga Psicodramatista (Locus Psicodrama). Especialista em Enfrentamento à Violência Contra Crianças e Adolescentes (PUC-PR). Mestranda em Educação/Psicologia do Desenvolvimento (Universidade Federal do Paraná). Rua Inácio Bastos, 623, Bucarein, CEP 89202-310. Joinville, SC. Tel.: (47) 3026-5230.

Márcia Pereira Bernardes. Psicodramatista Didata Supervisora pela FEBRAP. Doutoranda em Psicologia pela Universidade Federal de Santa Catarina. Avenida Othon Gama D'Eça, 900/903 Centro. CEP 88015-240. Florianópolis, SC. Tel.: (48) 9914-0141. E-mail: marcia@locuspsicodrama.com.br 